\title{
Isoenzymes of manganese-dependent peroxidase and laccase produced by the lignin- degrading basidiomycete Ceriporiopsis subvermispora
}

\author{
Sergio Lobos, ${ }^{1} \dagger$ Juan Larraín, ${ }^{1}$ Loreto Salas, ${ }^{1}$ Daniel Cullen ${ }^{2}$ and \\ Rafael Vicuña ${ }^{1}$
}

Author for correspondence: Rafael Vicuna. Tel: +562222 1199. Fax: +5622225515.

\footnotetext{
1 Laboratorio de Bioquímica, Facultad de Ciencias Biológicas, Pontificia Universidad Católica de Chile, Casilla 114-D, Santiago, Chile

2 Institute for Microbial and Biochemical Technology, Forest Products Laboratory, Forest Service, USDA, One Gifford Pinchot Drive, Madison, Wisconsin 53705, USA
}

\begin{abstract}
The white-rot basidiomycete Ceriporiopsis subvermispora produces two families of ligninolytic enzymes, namely manganese-dependent peroxidases (MnPs) and laccases, when growing in liquid cultures of defined composition. In medium containing 11 p.p.m. of $\mathrm{Mn}$ (II), up to seven isoenzymes of MnP and four isoenzymes of laccase were resolved by isoelectrofocusing (IEF), with pl values in the range $4 \cdot 10-4 \cdot 60$ and $3 \cdot 45-3 \cdot 65$, respectively. Occasionally, a fifth laccase isoform of pl 4.70 was also detected. In cultures with 25 and 40 p.p.m. of Mn(II), mainly the MnPs with higher pl values are produced. The isoenzyme pattern of MnP is not altered throughout the growth period of the fungus. MnP and laccase are also produced by C. subvermispora when growing on wood chips of Pinus radiata. Highest levels of both enzymes were obtained during the first week of incubation. A second peak of MnP activity was observed during the fourth week, whereas very low levels of laccase were extracted from the chips after the second week of growth. IEF analysis showed that the pl values of these laccases are similar to those of laccases produced in liquid cultures, being in the range 3.45-3.65. In contrast, four isoforms of MnP were resolved during the first week of incubation on wood chips, with pl values of 4.40, 4.17, 4.04 and 3.53. This profile underwent a transition during the second week of growth, at the end of which isoforms of MnP with pl values of 3.53, 3.40, 3.30 and 3.20 were resolved by IEF. Immunoblotting studies showed that the molecular mass of MnP isoenzymes from liquid cultures was about $52.5 \mathrm{kDa}$, whereas the molecular masses of MnPs extracted from wood varied from $52.5 \mathrm{kDa}$ to $62.5 \mathrm{kDa}$ upon ageing of the cultures. The amino terminal sequences of seven MnP isoenzymes were determined. The consensus sequences of MnPs from liquid and solid cultures were clearly distinct, although both showed homology to MnPs from related white-rot fungi.
\end{abstract}

Keywords: Ceriporiopsis subvermispora, manganese-dependent peroxidases, laccase, ligninolytic enzymes

\section{INTRODUCTION}

The white-rot basidiomycete Ceriporiopsis subvermispora is strongly ligninolytic (Otjen et al., 1987; Blanchette et al.,

†Permanent address: Facultad de Ciencias Químicas y Farmacéuticas, Universidad de Chile.

Abbreviations: ABTS, 2,2'-azino-bis(3-ethylbenzthiazoline-6-sulfonic acid); IEF, isoelectrofocusing; LiP, lignin peroxidase; MnP, manganesedependent peroxidase; PVDF, polyvinylidene difluoride.
1992) and it is used extensively in pilot-scale studies of biomechanical pulping (Akhtar et al., 1992, 1993). However, relative to other white-rot fungi such as Phanerocbaete chrysosporium, Coriolus versicolor or Pblebia radiata little is known concerning the enzymology of lignin degradation by $C$. subvermispora.

Studies with liquid cultures of $C$. subvermispora have demonstrated the production of two classes of extracellular enzymes: manganese-dependent peroxidases 
(MnPs) and laccases (Ruttimann et al., 1992a, b). Levels of these enzymes are positively correlated with lignin mineralization in $C$. subvermispora (Ruttimann-Johnson $e t$ al., 1993). Lignin peroxidase (LiP) has not been detected in cultures of this fungus grown under a wide variety of conditions (Ruttimann et al., 1992a, b).

$\mathrm{MnPs}$ have been found in several fungal species (Orth $e t$ al., 1993). In Phanerochaete chrysosporium, at least six isoenzymes have been identified (Leisola et al., 1987). Amino-terminal sequence analyses show that they are encoded by at least four genes (Leisola et al., 1987; Pease $\&$ Tien, 1992), two of which have been cloned and characterized (Pease et al., 1989; Pribnow et al., 1989). These isoenzymes are differentially regulated in resporse to nutrient limitation and culture age (Pease \& Tien, 1992). MnPs have also been partially characterized from Panus tigrinus (Maltseva et al., 1991), Dichomitus squalens (Périé \& Gold, 1991), Rigidoporus lignosus (Galliano et al., 1991), Pblebia radiata (Karhunen et al., 1990), Lentinula edodes (Forrester et al., 1990), Phanerocbaete sordida (Ruttimann-Johnson et al., 1994) and Coriolus versicolor (Johansson \& Nyman, 1993; Johansson et al., 1993), among others. Its wide distribution among ligninolytic fungi suggests that $\mathrm{MnP}$ may play a key role in the process of lignin biodegradation.

Laccase activity has also been detected in numerous fungi, including several lignin-degraders. Among the latter. Coriolus versicolor (Morohoshi, 1991), Panus tigrinus (Maltseva et al., 1991) and R. lignosus (Geiger et al., 1986) produce multiple isoenzymes, whereas Phlebia radiata secretes only one species of laccase to the extracellular medium (Niku-Paavola et al., 1988). Genes encoding laccase activity in several white-rot ligninolytic fungi have been cloned and characterized (Saloheimo et al., 1991; Kojima et al., 1990; Iimura et al., 1992; Coll et al., 1993).

Most studies of ligninolytic enzymes have been conducted with preparations isolated from liquid cultures of the various fungal strains utilized. Moreover, since liquid cultures are easy to manipulate, conditions have been developed in several cases for optimal enzyme production and lignin mineralization. Although this approach has been a valuable tool for understanding several aspects of the lignin biodegradation process, white-rot fungi normally exert their action while growing on solid wood. Therefore, it seems reasonable to compare the ligninolytic enzymes produced by white-rot fungi growing in liquid cultures with their counterparts produced in solid state cultures. Some knowledge has already been gained in this respect with Pbanerochaete chrysosporium; Datta et al. (1991) reported that the most abundant peroxidase extracted from cultures of this organism growing on wood pulp is $\mathrm{MnP}$ rather than LiP.

In this work we describe multiple $\mathrm{MnP}$ and laccase isoenzymes from Ceriporiopsis subvermispora and their production in both liquid and solid state cultures.

\section{METHODS}

Organism. C. subvermispora strain FP-105752 was obtained from the Center for Forest Mycology Research, Forest Products
Laboratory, Madison, WI, USA. The fungus was maintained on agar slants of potato dextrose agar medium (Difco).

Growth in liquid cultures. Erlenmeyer flasks (125 ml) containing $30 \mathrm{ml}$ minimal salts medium (Ruttimann et al., 1992a) were inoculated with $13.5 \mathrm{mg}$ of homogenized mycelium prepared as previously described (Ruttimann et al., 1992a). Unless otherwise indicated, the medium contained 11 p.p.m. $(195 \mu \mathrm{M}) \mathrm{MnSO}_{4}$ and $10 \mathrm{mM}$ ammonium tartrate as nitrogen source.

Fractionation of enzymes produced in liquid cultures. One hundred millilitres of $15-\mathrm{d}$ cultures was centrifuged for $20 \mathrm{~min}$ at 10000 r.p.m. to remove the mycelium and the extracellular glucan. The supernatant was concentrated 20 -fold by ultrafiltration in a $185 \mathrm{ml}$ Amicon cell with a $10 \mathrm{kDa}$ cut-off membrane and dialysed against $10 \mathrm{mM}$ sodium acetate $\mathrm{pH} 6.0$. Protein $(50 \mathrm{mg})$ was loaded onto a Q-Sepharose (Pharmacia) column $\left(0.6 \mathrm{~cm}^{2} \times 27 \mathrm{~cm}\right)$ previously equilibrated with the same solution. Enzymes were eluted with a $60 \mathrm{ml}$ linear gradient of $10-600 \mathrm{mM}$ sodium acetate $\mathrm{pH} 6.0$ and $1 \mathrm{ml}$ fractions were collected. For preparative IEF (see below), fractions that were enriched in $\mathrm{MnP}$ activity were pooled and concentrated by dialysis against a $40 \%$ solution of polyethylene glycol 8000 dissolved in $10 \mathrm{mM}$ sodium acetate $\mathrm{pH} 6.0$, to a final protein concentration of about $1 \mathrm{mg} \mathrm{ml} \mathrm{m}^{-\mathbf{1}}$.

Growth on wood chips. Four millilitres of a defined medium (Leatham, 1983) containing $10 \mathrm{mM}$ ammonium tartrate and $2.5 \%(\mathrm{w} / \mathrm{v})$ glucose, plus $6 \mathrm{ml}$ water, were added to $15 \mathrm{~g}$ Pinus radiata chips $(5 \times 5 \mathrm{~mm}, 40 \%$ initial moisture content) in $250 \mathrm{ml}$ Erlenmeyer flasks. The flasks were covered with aluminium foil and autoclaved for $45 \mathrm{~min}$ at $121^{\circ} \mathrm{C}$, giving a final moisture content of $60 \%$. After cooling to room temperature, the chips were inoculated with two $1.0 \mathrm{~cm}^{2}$ mycelial plugs of the fungus grown on potato dextrose agar, and vigorously mixed. Flasks were incubated at $30^{\circ} \mathrm{C}$ for up to 4 weeks, being supplied with filtered and humidified air throughout this period $\left(1.51 \mathrm{~h}^{-1}\right)$.

Enzyme extraction from the wood chips and partial fractionation. Chips were resuspended for $1 \mathrm{~h}$ at $4{ }^{\circ} \mathrm{C}$ with occasional stirring in $30 \mathrm{ml} 50 \mathrm{mM}$ sodium acetate $\mathrm{pH} 4.8$ (buffer A). The liquid phase was centrifuged for $1 \mathrm{~h}$ at 15000 r.p.m. and the supernatant was diluted twofold with water. The solution obtained was loaded onto a $2 \mathrm{ml}$ Q-Sepharose column equilibrated with buffer $A$. Enzymes were eluted stepwise with $4 \mathrm{ml}$ solutions of $\mathrm{NaCl}(0 \cdot 1,0 \cdot 2,0 \cdot 3$, and $0.4 \mathrm{M})$ in buffer $\mathrm{A}$. Both enzymes were always recovered in the fraction containing $0.2 \mathrm{M}$ $\mathrm{NaCl}$. During the first week, some additional $\mathrm{MnP}$ activity also eluted with $0 \cdot 1 \mathrm{M} \mathrm{NaCl}$. This fractionation procedure was scaled up prior to preparative IEF.

Enzyme assays. $\mathrm{MnP}$ and laccase were assayed as previously described (Ruttimann et al., 1992a), using vanillylacetone and ABTS (Sigma) as substrates, respectively. LiP activity was measured using two standard methods (Tien \& Kirk, 1984; Archibald, 1992). Definitions of enzyme units have been reported previously (Ruttimann et al., 1992a).

Isoelectrofocusing. IEF was performed over the $\mathrm{pH}$ range 3-6, using Servalyt Precotes 3-6 polyacrylamide gels from Serva. After applying the protein samples $(0 \cdot 5-1 \cdot 0 \mu \mathrm{g}$ protein per well in analytical gels, $200-400 \mu \mathrm{g}$ in preparative gels), gels were run for $30 \mathrm{~min}$ at $200 \mathrm{~V}, 15 \mathrm{~min}$ at $400 \mathrm{~V}, 5 \mathrm{~min}$ at $800 \mathrm{~V}$ and then the voltage was raised to $1200 \mathrm{~V}$ until the current reached $2 \mathrm{~mA}$. $\mathrm{MnP}$ bands were developed by soaking the gel in a solution prepared as follows: $15 \mathrm{mg}$ 4-chloro-1-naphthol was dissolved in $5 \mathrm{ml}$ methanol; $1 \mathrm{ml}$ of this solution was mixed with $6.3 \mathrm{ml}$ $20 \mathrm{mM}$ Tris/ $\mathrm{HCl} \mathrm{pH} \mathrm{7.5,0.5} \mathrm{M} \mathrm{NaCl}$. In turn, $4 \mathrm{ml}$ of the 
resulting solution was mixed with $25 \mathrm{ml} 50 \mathrm{mM}$ sodium tartrate $\mathrm{pH} 5.0$ containing $0.2 \mathrm{mM} \mathrm{MnSO}_{4}$. Hydrogen peroxide was added to a final concentration of $50 \mathrm{mM}$. The solution for developing the bands corresponding to laccase was the same but lacked $\mathrm{MnSO}_{4}$ and hydrogen peroxide. Occasionally, both enzymes were developed with ABTS or phenol red as substrates, which were present at final concentrations of $5 \mathrm{mM}$ and $480 \mu \mathrm{M}$ respectively. When indicated, 1 unit $\mathrm{ml}^{-1}$ of catalase (Sigma) was added to the developing solution of laccase activity. Standards for IEF were all from Sigma: amyloglucosidase from Aspergillus niger (pI 3.6), glucose oxidase from Aspergillus niger (pI $4 \cdot 2$ ), soybean trypsin inhibitor (pI 4.6), $\beta$-lactoglobulin A from bovine milk (pI 5.1), carbonic anhydrase II from bovine erythrocytes (pI 5.4 and 5.9) and carbonic anhydrase I from human erythrocytes (pI 6.6). Preparative IEF gels were always performed with protein which had been fractionated previously by Q-Sepharose chromatography.

Anti-MnP antibody. MnP was purified from 25 -d solid state cultures. Proteins extracted from $200 \mathrm{~g}$ of dry wood chips were first fractionated by Q-Sepharose chromatography. Active fractions were pooled, concentrated first to $10 \mathrm{ml}$ by ultrafiltration in an Amicon cell and then to $0.5 \mathrm{ml}$ in a Millipore cartridge (10000 cut-off). Protein (1 mg) was applied to preparative Servalyt Precotes. The IEF gel section containing the $\mathrm{MnP}$ bands was excised and homogenized to a final volume of $0.6 \mathrm{ml}$ with $50 \mathrm{mM}$ Tris/ $\mathrm{HCl}$ buffer $\mathrm{pH} 7.5$ containing $200 \mathrm{mM} \mathrm{NaCl}$. The suspension was extensively dialysed against PBS solution (8.1 mM Na $\mathrm{HPO}_{4}, 1.47 \mathrm{mM} \mathrm{KH_{2 }} \mathrm{PO}_{4}, 0.8 \%$ $\mathrm{NaCl}, 0 \cdot 02 \% \mathrm{KCl}$ ). A rabbit was initially injected subcutaneously with $300 \mu \mathrm{g} \mathrm{MnP}$ protein in complete Freund's adjuvant. Two $300 \mu \mathrm{g}$ aliquots of $\mathrm{MnP}$ in incomplete Freund's adjuvant were injected 15 and $25 \mathrm{~d}$ after the first injection. Antibody titre was monitored by ELISA assays.

Western blots. Proteins ( $300 \mathrm{ng}$ per track) and prestained molecular mass markers (Sigma) were first separated by SDSPAGE and then transferred to nitrocellulose for $50 \mathrm{~min}$ at room temperature and $150 \mathrm{~mA}$, in a BioRad chamber with a solution of $25 \mathrm{mM}$ Tris/ $\mathrm{HCl} \mathrm{pH} 8.4,192 \mathrm{mM}$ glycine and $20 \%(\mathrm{v} / \mathrm{v})$ methanol. The nitrocellulose was incubated with gentle agitation for $30 \mathrm{~min}$ at room temperature in PBS solution containing $1 \%(\mathrm{w} / \mathrm{v})$ bovine serum albumin (PBS-BSA) and thereafter immersed in serum anti-MnP diluted 10-fold in PBS-BSA for an additional $30 \mathrm{~min}$. The nitrocellulose was washed six times for 1 min with PBS solution containing $0 \cdot 1 \%$ Tween 20 and incubated for $30 \mathrm{~min}$ in a $1 / 3500$ dilution in PBS-BSA of horseradish peroxidase conjugated to antibody anti-IgG from rabbit (BioRad). The nitrocellulose was washed as before and developed by soaking it for 5--15 $\mathrm{min}$ in a mixture containing $10 \mathrm{ml} 50 \mathrm{mM}$ Tris/ $\mathrm{HCl}$ buffer $\mathrm{pH} \mathrm{7.4,} 200 \mathrm{mM}$ $\mathrm{NaCl}, 2 \mathrm{ml}$ of methanol containing $6 \mathrm{mg}$ 4-chloro-1-naphthol and $4 \mu \mathrm{l} 30 \%(\mathrm{v} / \mathrm{v})$ hydrogen peroxide.

Protein electroblotting and sequencing. After IEF, the MnP bands were excised and homogenized to a final volume of $0.2 \mathrm{ml}$ with $50 \mathrm{mM}$ Tris/ $\mathrm{HCl}$ buffer $\mathrm{pH} 7.5$ containing $200 \mathrm{mM} \mathrm{NaCl}$. Suspensions were loaded onto a $8 \%(\mathrm{w} / \mathrm{v})$ SDS-polyacrylamide gel and electrophoresed at $20 \mathrm{~mA}$ constant current. Purified isoenzymes were electroblotted to PVDF membranes (Matsudaira, 1987) and sequenced on an Applied Biosystems gas phase 475 protein sequencer at the University of Wisconsin Biotechnology Center.

Other procedures. SDS-PAGE was performed as reported by Laemmli (1970) and the protein bands were stained using a silver stain kit (Sigma). Protein concentration was measured by the method of Bradford (1976).

\section{RESULTS}

\section{Isoenzymes produced in liquid cultures of defined composition}

Extracellular minimal medium from 15-d cultures of $C$. subvermispora was subjected to IEF as indicated in Methods. The gel was cut into four sections, which were developed under different conditions (Fig. 1). When the developing solution contained only the substrate - in this case 4-chloro-1-naphthol - several staining bands were observed between pH 3.45 and 3.65 (Fig. 1, lane 1). These bands were also observed when catalase was present in the developing solution, indicating that they correspond to isoforms of laccase. Further addition of hydrogen peroxide or $\mathrm{Mn}(\mathrm{II})$ to the developing solution did not significantly alter the band patterns (Fig. 1, lanes 2 and 3, respectively). However, when these two components were added simultaneously, several bands appeared between $\mathrm{pH} 4 \cdot 1$ and $4 \cdot 6$, strongly suggesting that the latter correspond to isoforms of MnP (Fig. 1, lane 4). Thus, IEF provides a useful tool not only to separate isoenzymes but also, in this case, to differentiate activities of $\mathrm{MnP}$ and laccase. The same band pattern was obtained when ABTS or phenol red were used as substrates in the developing solution.

Attempts were made to find conditions leading to preferential production of particular isoforms of each activity. For this purpose, the effects of $\mathrm{Mn}(\mathrm{II})$ and culture age were analysed. Standard cultures of $C$. subvermispora contain 11 p.p.m. of $\mathrm{Mn}(\mathrm{II})$, since at this concentration the titres of both $\mathrm{MnP}$ and laccase are highest (Ruttimann et al., 1992a). Therefore, for comparative purposes, the fungus was grown in salt medium containing $0 \cdot 3,11,25$ and 40 p.p.m. of $\mathrm{Mn}(\mathrm{II})$ and the isoenzymes were analysed by IEF (Fig. 2). With 11 p.p.m. of Mn(II) in the medium, the expected MnP pattern was obtained (Fig. 2a, lane 2; compare with Fig. 1, lane 4). At Mn(II) concentrations of 25 and 40 p.p.m., the $\mathrm{MnP}$ isoforms of higher $\mathrm{pI}$ were preferentially produced (Fig. 2a, lanes 3 and 4 ). In the case of laccase, an isoform of pI 4.7 was present in the cultures

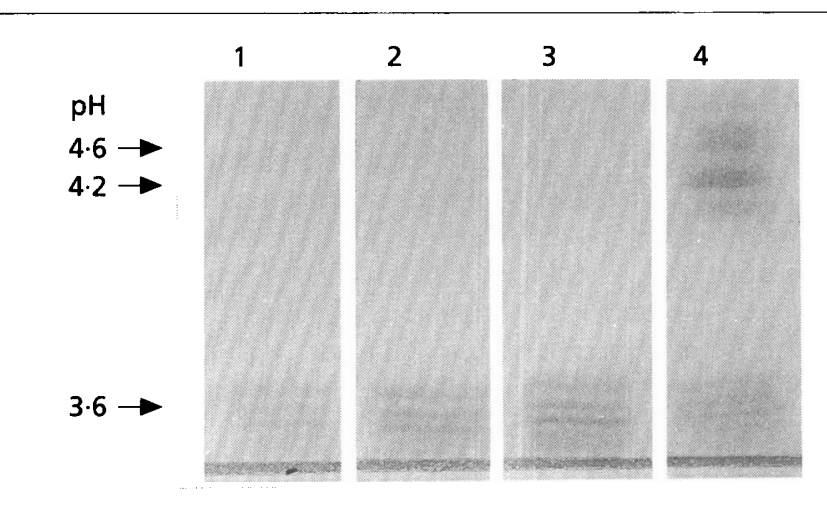

Fig. 1. IEF analysis of ligninolytic enzymes produced by $C$. subvermispora in liquid cultures of defined composition. Each gel was developed in a solution containing 4-chloro-naphthol as substrate, plus: no further addition (lane 1); hydrogen peroxide (lane 2); $\mathrm{Mn}$ (II) (lane 3); and hydrogen peroxide plus $\mathrm{Mn}(\mathrm{II})$ (lane 4). 
(a)

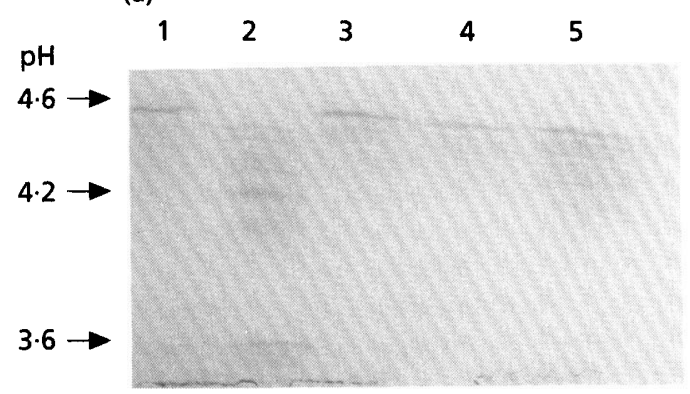

(b)

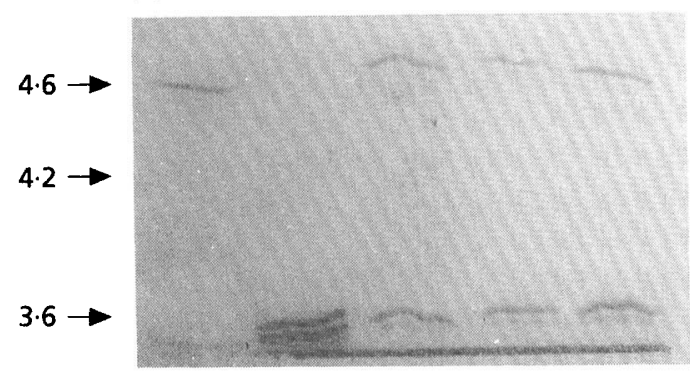

Fig. 2. Isoenzyme profile of MnP (a) and laccase (b) in cultures of $C$. subvermispora in minimal salts medium containing different concentrations of $\mathrm{Mn}(\mathrm{II})$. Lanes: 1, 0.3 p.p.m.; 2, 11 p.p.m.; 3, 25 p.p.m.; 4 and 5, 40 p.p.m. Lanes 1-4 each contain $3 \mu \mathrm{g}$ total protein. Lane 5 in each gel was loaded with the same quantity of activity units of $\mathrm{MnP}$ and laccase as was loaded onto the respective lane 4 . The activities of $\mathrm{MnP}$ (units $\mu \mathrm{g}$ protein ${ }^{-1}$ ) in the samples loaded onto lanes 1-4 were, respectively, $15.5,24.1,11.4$ and 11.0 . The activities of laccase were $3 \cdot 4,31 \cdot 8,3 \cdot 4$ and $2 \cdot 9$, respectively.

containing $0 \cdot 3,25$ and 40 p.p.m. of $\mathrm{Mn}(\mathrm{II})$, but not in the culture with 11 p.p.m. of $\mathrm{Mn}$ (II) (Fig. 2b). In the course of these studies, this band of laccase activity was only occasionally detected in the various cultures, even in those with 11 p.p.m. of $\mathrm{Mn}(\mathrm{II})$. The conditions that favour the formation of this laccase of high $\mathrm{pI}$ or its relation to the low $\mathrm{pI}$ isoforms are not yet known. On the other hand, samples were withdrawn from standard cultures of $C$. subvermispora throughout the growth period and analysed by IEF. Both isoenzyme patterns remained unaltered until the last day tested (day 25; data not shown).

To isolate isoforms of each enzyme, extracellular fluid from liquid cultures of $C$. subvermispora was fractionated by Q-Sepharose chromatography as indicated in Methods. After applying a shallow salt gradient, broad peaks of $\mathrm{MnP}$ and laccase activities were obtained, with partial resolution between these two enzymes. MnP- and laccaseenriched fractions were pooled separately and each pool was subjected to IEF (Fig. 3).

\section{Isoenzymes produced by C. subvermispora while growing in wood chips}

When $C$. subvermispora was inoculated onto wood chips of radiata pine, fungal growth became visible on day 4 . Enzymes produced by the fungus were extracted at

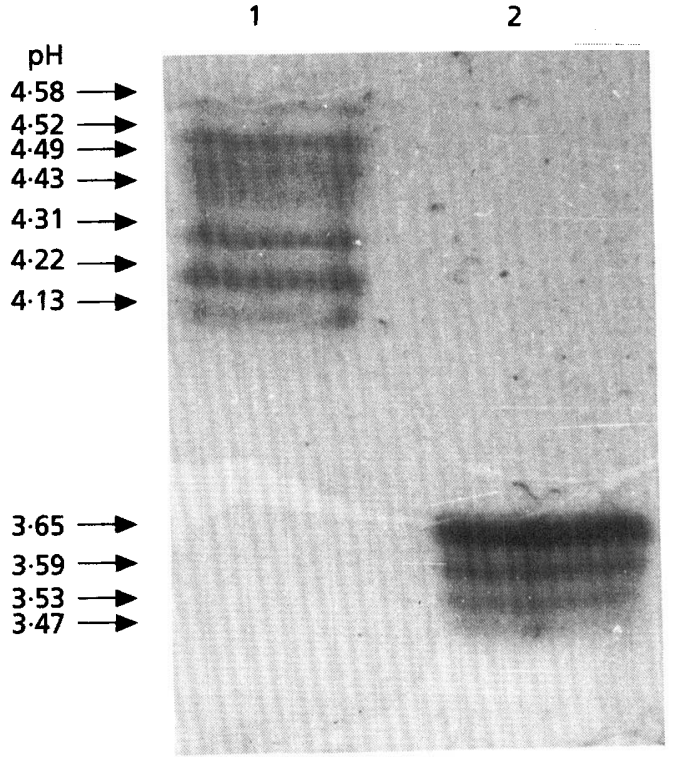

Fig. 3. IEF of MnP (1) and laccase (2) isoforms after fractionation by Q-Sepharose chromatography. The laccase of pl 4.7 is not observed in this sample.

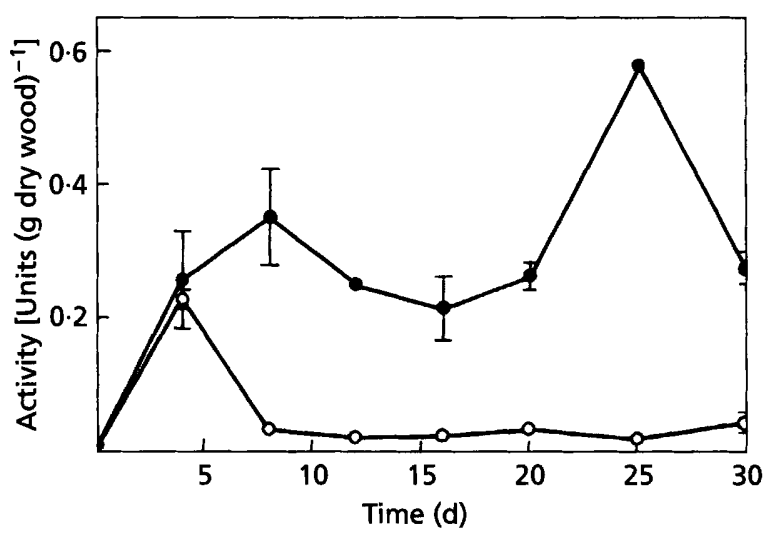

Fig. 4. Activity profile of $\mathrm{MnP}(0)$ and laccase $(0)$ extracted from wood chips at various times of fungal growth. Vertical bars represent a single standard error.

various times from the chips and separated by QSepharose chromatography from potential inhibitory substances released from the wood (see Methods). Under the standard conditions, $\mathrm{MnP}$ exhibited two peaks of activity, on days 8 and 25, whereas laccase activity reached its maximum during the first week of growth (days 4-5, Fig. 4). Thereafter, the levels of laccase began to decrease, reaching very low levels beyond the second week of incubation (Fig. 4).

IEF analysis throughout the culture period showed that the pattern of $\mathrm{MnP}$ isoforms extracted from the chips was different from that obtained in liquid cultures. At day 4, few distinct bands were observed (Fig. 5a, lane 1). Two of 
(a)

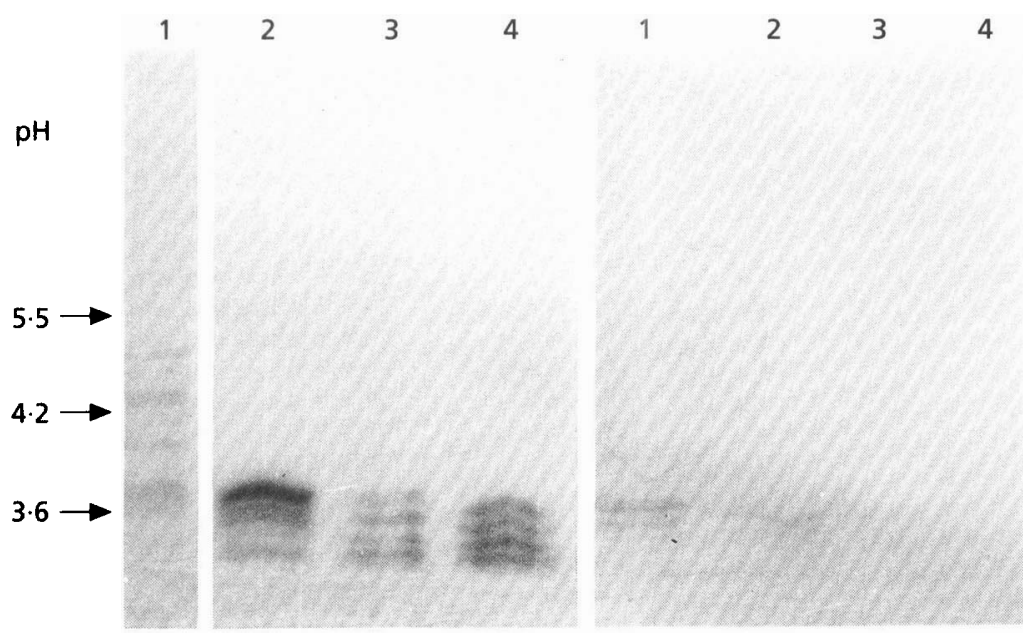

Fig. 5. IEF analysis of MnP (a) and laccase (b) extracted from wood chips at different times of fungal growth. Samples are $0.2 \mathrm{M}$ sodium acetate eluates of Q-Sepharose columns loaded with extracts obtained on days 4 (lanes 1), 8 (lanes 2), 16 (lanes 3) and 25 (lanes 4).

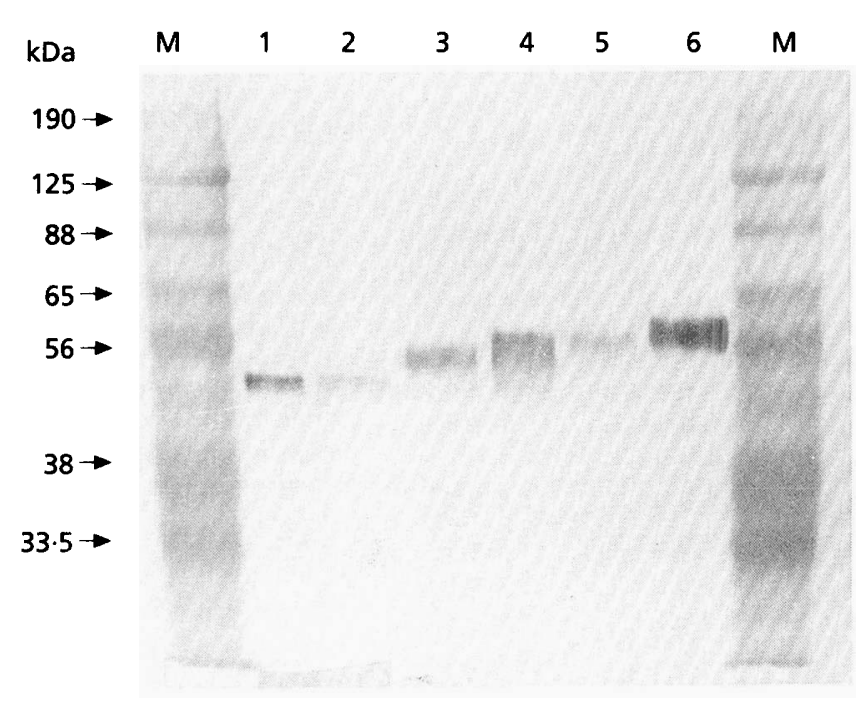

Fig. 6. Immunoblot analysis of MnPs at various times of fungal growth. Lane 1, MnP from liquid cultures in salt medium; lanes 2 and $3,0.1$ and $0.2 \mathrm{M} \mathrm{NaCl}$ eluates from Q-Sepharose column obtained by fractionation of protein extracted from wood chips at day 4; lanes 4-6, MnP extracted from wood chips at days 10, 16 and 25, respectively. M, Molecular mass markers.

them exhibited $\mathrm{pI}$ values of $4 \cdot 40$ and $4 \cdot 17$, which are in the same range as MnPs from liquid cultures. However, there were two additional $\mathrm{MnP}$ isoforms with $\mathrm{pI}$ values of 4.04 and 3.53 , that had not been identified previously. At day 8 and thereafter, four isoforms with pI values $3 \cdot 53,3 \cdot 40$, 3.30 and 3.20 were observed (Fig. 5 a, lanes $2-4$ ). These are all in the $\mathrm{pI}$ range of laccases isolated either from liquid cultures (Fig. 1) or from wood chip cultures (Fig. 5b, lanes 1 and 2). However, the bands observed in Fig. 5(a), lanes 2-4 can be ascribed to $\mathrm{MnP}$ activity, since laccases were not detected by IEF after the second week when the same samples were applied to the gel (Fig. 5b, lanes 3 and 4 ; see also the activity profile in Fig. 4).

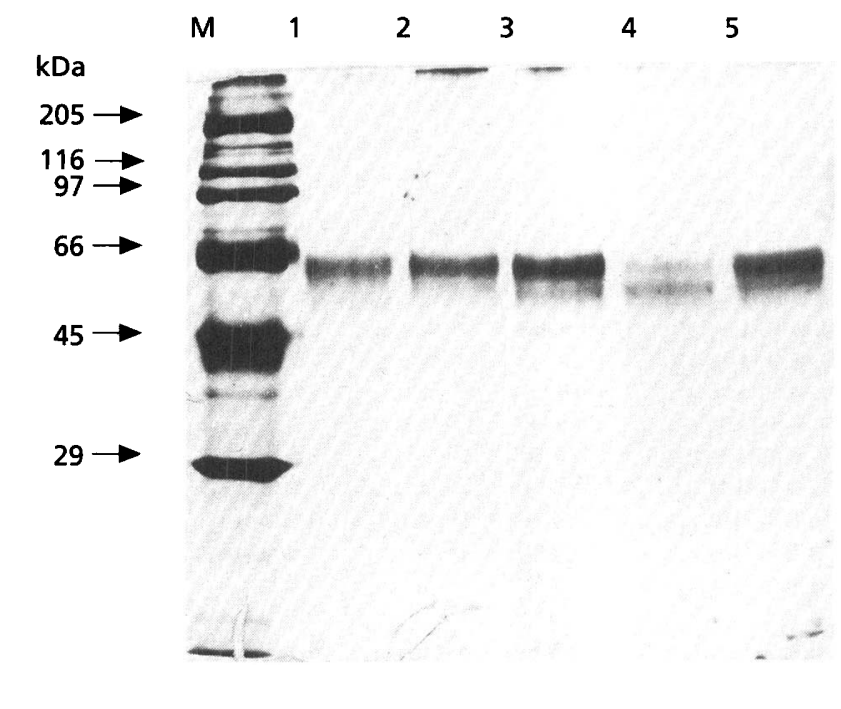

Fig. 7. SDS-PAGE (10\% gel) of MnPs obtained on day 25 , after preparative IEF. Lanes 1-4, MnPs of pl 3.20, 3.30, 3.40 and 3.53, respectively; lane $5, \mathrm{MnP}$ sample prior to IEF fractionation. In this experiment, $0.5 \mu \mathrm{g}$ protein was applied to each track. $M$, Molecular mass markers.

\section{Molecular mass of MnPs}

Samples from a culture of $C$. subvermispora in wood chips were obtained at various times of growth and analysed by immunoblotting (Fig. 6). In this analysis, a sample from a liquid culture in salt medium withdrawn at day 11 was also included. Some of the bands developed with this technique were broad, probably due to the presence of several isoforms in the corresponding samples. However, it is clear that the molecular mass of MnPs from a liquid culture $(52.5 \mathrm{kDa})$ was lower than that of MnPs from solid state culture obtained at day $25(62.5 \mathrm{kDa})$ (Fig. 6, lanes 1 and 6). Moreover, the molecular mass of the MnPs extracted from the wood chips gradually changed during the growth period. On day 4, Q-Sepharose chroma- 
(a) A I F P A G T R V S N F V R

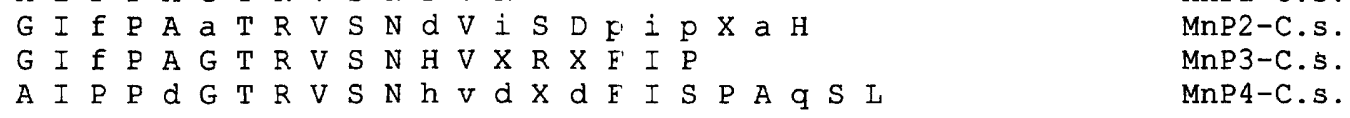

MnP1-C.s.

MnP2-C.s.

MnP3-C.s.

A I F P A G T R V S N H V. D F I P. A

consensus 1

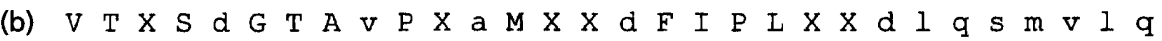

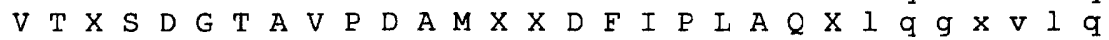

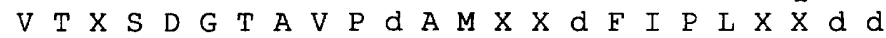

MnP5-C.s.

MnP6-C.s.

MnP7-C.s.

V T X S D G T A V D A M X X F I P L X X D $Q$. V $\mathrm{L} Q$ consensus 2

(c)

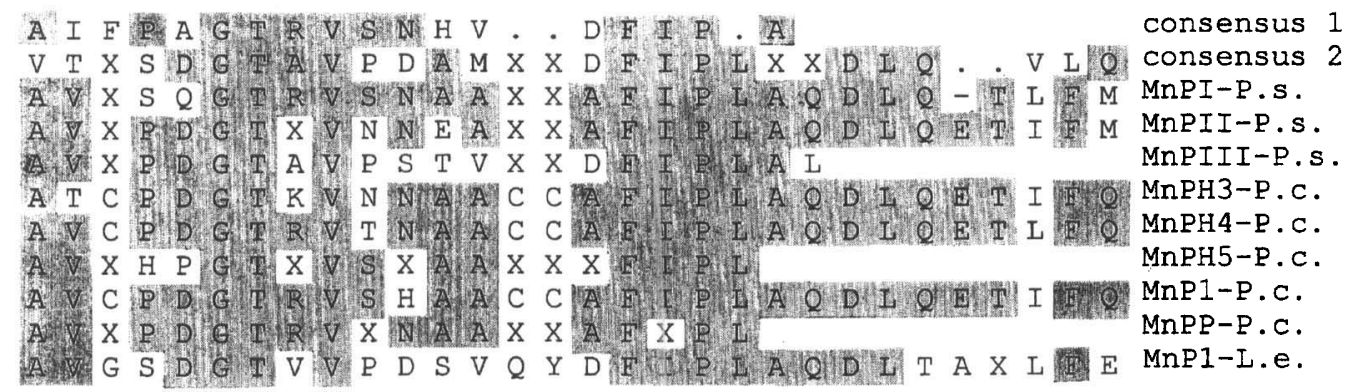

Fig. 8. Aligned $\mathrm{N}$-terminal sequences of $\operatorname{MnPs}$. $(a, b)$ Isoenzymes derived from liquid and solid media, respectively. Isoenzyme pl values were: MnP1-C.s., 4.2; MnP2-C.s., 4.3; MnP3-C.s., 4.4; MnP4-C.s., 4.6; MnP5-C.s., 3.4; MnP6-C.s., 3.3 and MnP7-C.s., 3.2. Lower-case letters indicate less confident assignments and the letter $X$ represents unknown residues. (c) The consensus sequences from $C$. subvermispora are compared to experimentally-determined sequences from: Phanerochaete sordida isoenzymes MnPI-P.S., MnPII-P.s., MnPIII-P.s. (Ruttimann-Johnson et al., 1994); Phanerochaete chrysosporium isoenzyme H5, MnPH5-P.c. (Pease \& Tien, 1992); a Phanerochaete chrysosporium isoenzyme purified from aspen pulp, MnPP-P.c. (Datta et al., 1991); and the Lentinula edodes MnP, MnP1-L.e. (Forrester et al., 1990). Sequences were deduced from CDNAs for isoenzymes MnPH3-P.C. (A. Orth and others, unpublished), MnPH4-P.c. (Pease et al., 1989) and MnP1-P.c. (Pribnow et al., 1989) from Phanerochaete chrysosporium. A gap was introduced in the MnPI-P.s. sequence to optimize alignment. Residues matching the consensus are shaded.

tography allowed the separation of MnPs with molecular masses of $52.5 \mathrm{kDa}$ and $57.5 \mathrm{kDa}$ (Fig. 6, lanes 2 and 3). Then, on day 10 , the average molecular mass increased to $60 \cdot 2 \mathrm{kDa}$ (Fig. 6, lane 4), to reach a final value of $62.5 \mathrm{kDa}$ on day 25.

After obtaining the isolated $\mathrm{MnPs}$ for $\mathrm{N}$-terminal sequencing, their molecular masses were determined by SDS-PAGE developed by silver staining. Isoforms from liquid cultures with $\mathrm{pI}$ values of $4 \cdot 21,4 \cdot 31,4 \cdot 43$, and $4 \cdot 58$ had a molecular mass of $52.5 \mathrm{kDa}$ (data not shown). In turn, isoenzymes from wood chips with pIs of $3 \cdot 20,3 \cdot 30$ and 3.40 showed a major band corresponding to a molecular mass of $62.5 \mathrm{kDa}$, whereas bands of 62.5 and $56 \mathrm{kDa}$ were observed in the sample of the isoform with a pI value of 3.53 (Fig. 7).

\section{$\mathrm{N}$-terminal sequence of some MnPs}

The $\mathrm{N}$-terminal sequences of $\mathrm{MnPs}$ with $\mathrm{pI}$ values of $4 \cdot 21$, $4.31,4.43$, and 4.58 from liquid cultures, as well as of $\mathrm{MnPs}$ with $\mathrm{pI}$ values of $3.20,3.30$ and 3.40 from solid cultures were determined. The four sequences of $\mathrm{MnPs}$ produced in liquid medium were highly similar although distinct, most mismatches involving residues with similar properties (Fig. 8a). In contrast, the $\mathrm{N}$-terminal sequences of the MnPs extracted from the wood chips could not be confidently differentiated, although the consensus sequence was different from the $\mathrm{N}$-terminal sequence of any $\mathrm{MnP}$ from salt medium (Fig. 8b). Pairwise comparisons with all published $\mathrm{MnP}$ sequences showed that $\mathrm{MnPs}$ from $C$. subvermispora were clearly related to those of other white-rot fungi (Fig. 8c). Database searches (SwissProt and PIR release 77) showed no significant homology to any other proteins, including the lignin peroxidases.

\section{DISCUSSION}

The basidiomycete Ceriporiopsis subvermispora secretes several isoenzymes of $\mathrm{MnP}$ and laccase when growing either in liquid cultures or in wood chips. This observation provides additional evidence that the multiplicity of ligninolytic enzymes is a common feature among white-rot fungi, although the physiological significance of this phenomenon is not yet completely understood. The $\mathrm{MnPs}$ isolated from solid state cultures differ from those produced in salt medium, although at this stage it would be premature to speculate which isoforms are more relevant to lignin degradation. 
The isoenzyme profile remains the same during growth of $C$. subvermispora in liquid cultures, although changes in the composition of the medium influence enzyme production by this fungus. For example, variations in the concentration of $\mathrm{Mn}(\mathrm{II})$ in salt medium or growth on a solid substrate lead to different isoenzyme patterns. Moreover, the isoenzyme profile in wood chips varies upon ageing of the culture. In early cultures, while externally added nutrients are still present, MnPs produced are similar in $\mathrm{pI}$ and molecular mass to those from liquid cultures. Later, when the nature of the growth substrate changes as the fungus proliferates into the wood, MnPs with lower $\mathrm{pI}$ values and higher molecular masses are secreted.

In Phanerochaete chrysosporium, the most thoroughly studied ligninolytic fungus, the expression of LiP and MnP genes is finely regulated. These enzymes are produced only during secondary metabolism. In addition, different isoenzyme patterns are observed upon ageing of the cultures (Pease \& Tien, 1992), changes in the composition of the medium (Leisola et al., 1987; Pease \& Tien, 1992; Das \& Reddy, 1990), or at different concentrations of Mn(II) (Bonnarme \& Jeffries, 1990; Pease \& Tien, 1992). Moreover, Phanerochaete chrysosporium produces a specific isoform of $\mathrm{MnP}$ during solid substrate degradation (Datta et al., 1991). It is conceivable, therefore, that at least some features of the regulatory mechanisms of the ligninolytic systems of Phanerochaete chrysosporium and C. subvermispora may be similar.

However, the ligninolytic systems of these two fungi are different: Phanerochaete chrysosporium produces LiP but not laccase. Systematic searches for LiP activity in defined medium (Ruttimann et al., 1992a, b; Ruttimann-Johnson et al., 1993) and in wood chips (this work) have failed to detect production of Lip by $C$. subvermispora. With respect to laccase, the multiple isoforms isolated from liquid cultures of $C$. subvermispora appeared similar to those extracted from the wood chips. The latter were confined to early stages of fungal growth. It is possible that this enzyme may also be produced in late cultures, but for reasons such as adherence to wood or to the mycelium, inaccessibility to the extraction buffer, proteolytic inactivation, etc., its activity is underestimated.

In general, multiple isoforms may result from the expression of different genes, the expression of alleles of the same gene or post-translational processing. An example of the first possibility is provided by the LiPs from Phanerochaete chrysosporium (Cullen \& Kersten, 1992). In contrast, the presence of allelic variants encoding isoenzymes with different $\mathrm{pI}$ values has been shown for glyoxal oxidase from Phanerochaete chrysosporium ( $P$. Kersten \& D. Cullen, unpublished). Finally, differential glycosylation of the same gene product may give rise to enzymes with different $\mathrm{pI}$ values. The $\mathrm{N}$-terminal sequences of four isoenzymes of $\mathrm{MnP}$ produced by $C$. subvermispora in liquid cultures were highly similar, but distinct. Thus, these isoenzymes may represent the products of separate genes, although allelic variation cannot be formally excluded in a basidiomycete such as $C$. subvermispora. In contrast, since the three $\mathrm{MnP}$ isoenzymes isolated from wood chips appear to exhibit the same $\mathrm{N}$-terminal sequence, the difference in their $\mathrm{pI}$ values may reflect variations in their carbohydrate moieties. On the other hand, their higher molecular mass compared to the $\mathrm{MnPs}$ from liquid cultures also points to the presence of more than one gene. To date, a multiplicity of $\mathrm{MnP}$ genes has been demonstrated only in Phanerochaete chrysosporium (Pease \& Tien, 1992; Pease et al., 1989; Pribnow et al., 1989). The role and interaction of these genes in lignin degradation remains to be established.

\section{ACKNOWLEDGEMENTS}

This work was financed by grants from National Science Foundation (NSF-INT 9121955), FONDECYT (0758/91) and the US Department of Energy (DE-FG02-87ER13712).

\section{REFERENCES}

Akhtar, M., Attridge, M. C., Myers, G. C., Kirk, T. K. \& Blanchette, R. A. (1992). Biomechanical pulping of loblolly pine with different strains of the white-rot fungus Ceriporiopsis subvermispora. Tappi J 75, 105-109.

Akhtar, M., Attridge, M. C., Myers, G. C. \& Blanchette, R. A. (1993). Biomechanical pulping of loblolly pine chips with selected white-rot fungi. Holvforschung 47, 36-40.

Archibald, F. S. (1992). A new assay for lignin-type peroxidases employing the dye Azure B. Appl Environ Microbiol 58, 3110-3116.

Blanchette, R. A., Burnes, T. A., Eerdmands, M. M. \& Akhtar, M. (1992). Evaluating isolates of Phanerochaete chrysosporium and Ceriporiopsis subvermispora for use in biological pulping processes. Holiforscbung 46, 109-115.

Bonnarme, P. \& Jeffries, T. W. (1990). Mn(II) regulation of lignin peroxidases and manganese-dependent peroxidases from lignindegrading white rot fungi. Appl Environ Microbiol 56, 210-217.

Bradford, M. M. (1976). A rapid and sensitive method for the quantitation of microgram quantities of protein utilizing the principle of protein-dye binding. Anal Biochem 72, 248-254.

Coll, P. M., Tabernero, C., Santa-María, R. \& Pérez, P. (1993). Characterization and structural analysis of the laccase I gene from the newly isolated ligninolytic basidiomycete PM1 (CECT 2971). Appl Environ Microbiol 59, 4129-4135.

Cullen, D. \& Kersten, P. (1992). Fungal enzymes for lignocellulose degradation. In Applied Molecular Genetics of Filamentous Fungi, pp. 100-131. Edited by J. R. Kinghorn \& G. Turner. London: Chapman and Hall.

Das, S. B. \& Reddy, C. A. (1990). Characterization of extracellular peroxidases produced by acetate-buffered cultures of the lignindegrading basidiomycete Pbanerochaete chrysosporium. FEMS Microbiol Lett 69, 221-224.

Datta, A., Bettermann, A. \& Kirk, T. K. (1991). Identification of a specific manganese peroxidase among ligninolytic enzymes secreted by Phanerochaete cbrysosporium during wood decay. Appl Environ Microbiol 57, 1453-1460.

Forrester, I. T., Grabski, A. C., Mishra, C., Kelley, B. L., Strickland, W. N., Leatham, G. F. \& Burgess, R. R. (1990). Characteristics and $\mathrm{N}$-terminal aminoacid sequence of a manganese peroxidase purified from Lentinula edodes cultures grown on commercial wood substrate. Appl Microbiol Biotechnol 33, 359-365.

Galliano, H., Gas, G., Seris, J. L. \& Boudet, A. M. (1991). Lignin degradation by Rigidoporus lignosus involves synergistic action of 
two oxidizing enzymes: Mn peroxidase and laccase. Enz Microb Technol 13, 478-482.

Geiger, J. P., Rio, B., Nandris, D. \& Nicole, M. (1986). Laccases of Rigidoporus lignosus and Phellinus noxius. Appl Biochem Biotechnol 12, 121-133.

limura, Y., Takenouchi, K., Nakamura, M., Kawai, S., Katayama, Y. \& Morohoshi, M. (1992). Cloning and sequence analysis of laccase genes and its use for a expression vector in Coriolus versicolor. In Biotechnology in the Pulp and Paper Industry, pp. 427-431. Edited by M. Kuwahara \& M. Shimada. Tokyo: UNI Publishers.

Johansson, T. \& Nyman, P. O. (1993). Isozymes of the lignin peroxidase and manganese (II) peroxidase from the white-rot basidiomycete Trametes versicolor. I. Isolation of enzyme forms and characterization of physical and catalytic properties. Arch Biochem Biopbys 300, 49-56.

Johansson, T., Welinder, K. G. \& Nyman, P. O. (1993). Isozymes of the lignin peroxidase and manganese (II) peroxidase from the white-rot basidiomycete Trametes versicolor. II. Partial sequences, peptide maps and aminoacid and carbohydrate compositions. Arch Biochem Biophys 300, 57-62.

Karhunen, E., Kantelinen, A. \& Niku-Paavola, M.-L. (1990). Mndependent peroxidase from the lignin-degrading white-rot fungus Pblebia radiata. Arch Biochem Biopbys 279, 25-31.

Kojima, Y., Tsukuda, Y., Kawai, Y., Tsukamoto, A., Sugiura, J., Sakaino, M. \& Kita, Y. (1990). Cloning, sequence analysis and expression of ligninolytic phenol oxidase genes of the white-rot basidiomycete Coriolus birsutus. J Biol Chem 265, 15224-15230.

Laemmli, U. K. (1970). Cleavage of structural proteins during: the assembly of the head of bacteriophage T4. Nature 227, 680-635.

Leatham, G. F. (1983). A chemically defined medium for the fruiting of Lentinus edodes. Mycologia 75(5), 905-908.

Leisola, M. S. A., Kozulic, B., Meussdoerffer, F. \& Fiechter, A. (1987). Homology among multiple extracellular peroxidases from Phanerochaete chrysosporium. J Biol Chem 262, 419-424.

Maltseva, O. V., Niku-Paavola, M.-L., Leontievsky, A. A., Myasoedova, N. M. \& Golovleva, L. A. (1991). Ligninolytic enzymes of the white-rot fungus Panus tigrinus. Biotechnol Appl Biochem 13, 291-302.

Matsudaira, P. (1987). Sequence from picomole quantities of proteins electroblotted onto polyvinylidene difluoride membranes. J Biol Chem 262, 10035-10038.

Morohoshi, N. (1991). Laccases from the ligninolytic fungus Coriolus versicolor. In Enzymes in Biomass Conversion, ACS Symposium Series 460, pp. 207-204. Edited by G. Leatham \& M. E. Himmel. Washington, DC: American Chemical Society.

Niku-Paavola, M.-L., Karhunen, E., Salola, P. \& Raunio, V. (1988).
Ligninolytic enzymes of the white-rot fungus Phlebia radiata. Biochem J 254, 877-884.

Orth, A., Royse, D. J. \& Tien, M. (1993). Ubiquity of lignindegrading peroxidases among various wood-degrading fungi. $A p p l$ Environ Microbiol 59, 4017-4023.

Otjen, L., Blanchette, R., Effland, M. \& Leatham, G. (1987). Assessment of 30 white-rot basidiomycetes for selective lignin degradation. Holzforschung 41, 343-349.

Pease, E. A. \& Tien, M. (1992). Heterogeneity and regulation of manganese peroxidases from Phanerochaete chrysosporium. J Bacteriol 174, 3532-3540.

Pease, E. A., Andrawis, A. \& Tien, M. (1989). Manganesedependent peroxidases from Phanerochaete chrysosporium: primary structure deduced from cDNA sequence. $J$ Biol Chem 264, 13531-13535.

Périé, F. H. \& Gold, M. H. (1991). Manganese regulation of manganese peroxidase expression and lignin degradation by the white-rot fungus Dichomitus squalens. Appl Environ Microbiol 57, 2240-2245.

Pribnow, D., Mayfield, M. B., Nipper, V. J., Brown, J. A. \& Gold, M. H. (1989). Characterization of cDNA encoding a manganese peroxidase from the lignin-degrading basidiomycete Pbanerocbaete chrysosporium. J Biol Chem 264, 5036-5040.

Ruttimann, C., Schwember, E., Salas, L., Cullen, D. \& Vicuña, R. (1992a). Ligninolytic enzymes of the white-rot basidiomycetes Pblebia brevispora and Ceriporiopsis subvermispora. Biotechnol Appl Biochem 16, 64-76.

Ruttimann, C., Salas, L. \& Vicuña, R. (1992b). Studies on the ligninolytic system of the white-rot fungus Ceriporiopsis subvermispora. In Biotechnology in the Pulp and Paper Industry, pp. 243-248. Edited by M. Kuwahara \& M. Shimada. Tokyo: UNI Publishers.

Ruttimann-Johnson, C., Salas, L., Vicuña, R. \& Kirk, T. K. (1993). Extracellular enzyme production and synthetic lignin mineralization by Ceriporiopsis subvermispora. Appl Environ Microbiol 59, 1792-1797.

Ruttimann-Johnson, C., Cullen, D. \& Lamar, R, (1994). Manganese peroxidases of the white-rot fungus Phanerochaete sordida. Appl Environ Microbiol 60, 599-605.

Saloheimo, M., Niku-Paavola, M.-L. \& Knowles, J. K. C. (1991). Isolation and structural analysis of the laccase gene from the lignindegrading fungus Pblebia radiata. J Gen Microbiol 137, 1537-1544.

Tien, M. \& Kirk, T. K. (1984). Lignin-degrading enzyme from Phanerochaete chrysosporium: purification, characterization and catalytic properties of a unique $\mathrm{H}_{2} \mathrm{O}_{2}$-requiring oxygenase. Proc Natl Acad Sci US A 81, 2280-2284.

Received 16 March 1994; revised 5 May 1994; accepted 12 May 1994. 